\title{
Modeling Social Norms and Social Influence in Obesity
}

\author{
David A. Shoham • Ross Hammond • \\ Hazhir Rahmandad • Youfa Wang • \\ Peter Hovmand
}

Published online: 13 January 2015

(C) Springer International Publishing AG 2015

\begin{abstract}
The worldwide increase in obesity has led to changes in what is considered "normal" or desirable weight, especially among populations at higher risk. We show that social norms are key to understanding the obesity epidemic and that social influence mechanisms provide a necessary linkage between individual obesity-related behaviors and populationlevel characteristics. Because influence mechanisms cannot be directly observed, we show how three complex systems tools may be used to gain insights into observed epidemiologic patterns: social network analysis, agent-based modeling, and systems dynamics modeling. However, simulation and mathematical modeling approaches raise questions regarding acceptance of findings, especially among policy makers. Nevertheless, we point to modeling successes in obesity and other fields, including the NIH-funded National Collaborative on Childhood Obesity Research (NCCOR) Envision project.
\end{abstract}

This article is part of the Topical Collection on Social Epidemiology

D. A. Shoham $(\bowtie)$

Department of Public Health Sciences, Loyola University Chicago,

2160 S First Ave, Maywood, IL 60153, USA

e-mail: dshoham@luc.edu

R. Hammond

Center on Social Dynamics and Policy, The Brookings Institution, Washington, DC 20036, USA

H. Rahmandad

Department of Industrial and Systems Engineering, Virginia

Tech-Northern Virginia Center, Falls Church, VA 22043, USA

Y. Wang

Department of Social and Preventive Medicine, School of Public

Health and Health Professions, University at Buffalo, Buffalo,

NY 14214, USA

\section{P. Hovmand}

Social System Design Lab, George Warren Brown School of Social Work, Washington University in St. Louis, St. Louis, MO 63130, USA
Keywords Social influence $\cdot$ Norms $\cdot$ Social network analysis · Obesity · System dynamics modeling · Agent-based modeling $\cdot$ Social epidemiology $\cdot$ Health policy

\section{Introduction}

As obesity has become a global epidemic [1, 2], what is considered a "normal" or desirable body size has also increased, especially among certain racial-ethnic and gender groups [3-5]. A growing number of studies have found that body image is related to health behaviors including eating and dieting, particular among young people in the USA $[3,4,6]$, and thus affects obesity. A full understanding of the obesity epidemic is therefore likely to include social norms along with two related mechanisms: feedback between population-level characteristics and individual behavior, and the role of social networks in defining who is influencing whom. For example, a well-known study by Christakis and Fowler posits that social contacts of individuals directly or indirectly influence obesity-related behaviors and that social networks structure therefore shapes who becomes obese [7]. We call this the "social influence hypothesis," and in the following discussion, we will focus our attention on its application to obesity.

One source of confusion over the value or plausibility of the social influence hypothesis in the public health community is that models are often equated with correlational models, such as the one proposed by Christakis and Fowler. Epidemiologists and others have described the need for a priori specification of a causal mechanism in order to provide causal inference from such models [8,9], yet mechanisms may be unknown, disputed, or untested. However, correlational modeling is only one approach. Other types of models are possible, including informal mental models, maps representing a territory, and mechanistic models of behavioral 
and physical phenomena [10], such as the mathematical models of classical mechanics. Ultimately, a "model" is any simplified representation of reality that omits many details in order to provide insight into a problem [11]. Expanding the range of models epidemiologists utilize in research and policy analysis enables us to address more diverse problems and gain different types of insights. The need for a fuller range of models is especially pertinent to social epidemiology, as much of the field addresses issues that arise with social systems, including social influence. Particularly pressing are problems of endogeneity and feedback, which render statistical identification of causes difficult or impossible [12]. The remainder of this paper will address generative and mechanistic approaches to the problem of social influence with a focus on obesity. We expand on prior work summarizing the use of systems science tools in public health, including a recent article by Luke and Stamatakis [13•], by focusing on the issues of influence and norms.

Many types of social influences are theoretically possible, including mechanisms that do not involve norms such as market forces, advertising, neighborhood crime, and social capital. Natural experiments and randomized trials further suggest that social influence may be either permissive (encouraging behavior) or proscriptive (limiting behavior), depending on the (dis)similarity of those interacting. These mechanisms may suggest very different policies and interventions, including inoculation, induction, rewiring networks, identifying opinion leaders as champions, and de-normalizing of socially acceptable (but unhealthy) behavior [14•].

In this paper, we highlight how employing a broader range of models may help us understand the processes by which norm formation and change occur in a more direct way, helping researchers adjudicate some of these debates about what statistical signatures norms do or do not have. To that end, we will provide examples of approaches used by several teams who are members of the National Collaborative on Childhood Obesity Research (NCCOR) Envision network, including statistical, social network, agent-based, and system dynamics [15].

A second source of confusion related to the social influence hypothesis stems from different presuppositions about where social norms exist or "live." That is, do social norms exist as variables within individuals, as an emergent property of systems of individuals, or do they have an independent existence from individuals as part of the environment individuals observe and act within? The confusion arises in part because data about norms is collected from individuals, while the focus of study is usually effects at the aggregate level. Furthermore, norms are closely related to behaviors; as defined by Coleman, a norm concerning an action (which would include behaviors) exists "when the socially defined right to control the action [behavior] is held not by the actor but by others" ([16],p. 243). Deeper insights into dynamics that span both individual and collective levels may require new approaches that focus on mechanisms.

As the psychologist and philosopher of social science Paul Meehl noted, the problem here is not one of better statistical methods, but developing better theory specification through more explicit models [17]. In this paper, we recognize this by emphasizing the use of models to specify and test different formulations of the social influence hypothesis according to the type of influence or mechanisms. That is, rather than take a position on where social norms "live," we call for a more critical and pluralistic approach where norms are formulated according to the type of influence hypothesized. To support this, we provide the following taxonomy of influences in the form of logically plausible mechanisms (see Table 1).

The paper focuses on social influence as a mechanism shaping behavior. We do not claim that our provisional list of mechanisms in Table 1 is exhaustive; as noted above, many types of influence are possible. Nevertheless, the list encompasses a wide range of mechanisms operating at multiple levels and will serve to illustrate how these might be modeled. Social influence requires that there be at least two units interacting with one another. In what follows, we will refer to these units as "actors." While our focus is primarily on individual human beings as actors, we will also demonstrate the flexibility of the definition; for example, one type of actor may be a customer, and another a restaurant.

\section{Defining Social Influence}

Abraham and Michie [18] reviewed behavior change techniques that have been applied to physical activity and/or

Table 1 Taxonomy of social influence

\begin{tabular}{|c|c|c|c|c|}
\hline & $\begin{array}{l}\text { Population average } \\
\text { influences }\end{array}$ & $\begin{array}{l}\text { Dyad and subgroup } \\
\text { influences }\end{array}$ & Network influences & Society and cultural influences \\
\hline Influencing energy intake & $\begin{array}{l}\text { Increased expected portion } \\
\text { sizes }\end{array}$ & Sharing meals & Role models Fad diets & $\begin{array}{l}\text { Food advertising built environment } \\
\text { subsidies and taxes }\end{array}$ \\
\hline $\begin{array}{l}\text { Influencing desired body } \\
\text { weight }\end{array}$ & $\begin{array}{l}\text { Observed average body } \\
\text { size }\end{array}$ & Parental scolding & $\begin{array}{l}\text { Stigmatization bulking } \\
\text { up to avoid threats }\end{array}$ & Fashion ads \\
\hline $\begin{array}{l}\text { Influencing physical } \\
\text { activity }\end{array}$ & $\begin{array}{l}\text { Trends in active } \\
\text { commuting }\end{array}$ & Playing sports with others & Social approval of fitness & Neighborhood crime and walkability \\
\hline
\end{tabular}


healthy eating and other health risk behaviors (e.g., HIV/ AIDS). Eight of these techniques employ what might be considered social influence mechanisms: providing information on approval by others, providing encouragement, modeling or demonstrating a behavior, providing feedback on performance, using follow-up prompts, providing opportunities for social comparison, planning social support or change, and prompting identification as a role model. Many of these techniques are either explicitly drawn from, or can be tied to, wellestablished behavioral theories: theory of reasoned action [19], theory of planned behavior [20], information-motivation-behavioral skills [21], social cognitive theory [22], theory of social comparison [23], social support theory [24], and control theory [25]. These behavior change techniques are largely drawn from the clinical psychology and health behavior within the context of dyadic (therapist-patient) interactions.

While therapeutic relationships may serve as a model of one type of social interaction, social influence clearly extends beyond dyadic interactions to relationships between individuals and larger social and political systems. Kelman [26] proposed a framework of influence at operating at multiple levels, with three processes (compliance, identification, and internalization) linking individual behavior to norms outside the individual, shaped by the structure of social interaction. We therefore turn to social networks as a means of understanding this structure.

\section{Social Network Models}

We imagine that many types of norms arise from the local social environment, especially social networks. In turn, norms help shape and re-enforce social networks. In what follows, we focus on actor-by-actor (one-mode) networks. Networks are typically represented as graphs. Actors in a network are referred to as nodes, and relationships (including interactions) between nodes are represented as edges [27, 28]. A focal actor in a network (for example, a person filing out a questionnaire) is called an ego; egos have "neighbors" to which they are tied (friends, contacts), whom we refer to as alters. If the network is egocentric, all real-world information about the network is collected from, and revolves around, the ego; an example is the General Social Survey (GSS) [29]. If alters are also egos, then the network is sociometric; the National Longitudinal Study of Adolescent Health (Add Health) is a well-known example [30]. Specification of interaction without a network structure is also possible and, in many situations, is plausible [31].

The lowest level of interaction is the dyad, comprises of only two agents. Kelman's work (discussed above) examined influence within therapist-patient dyads [26]. Some intriguing experimental studies of dyadic interaction offer further insights into rules for people's behavior. Yakusheva et al. [32] studied college freshman women randomly assigned dormitory roommates; an ego rooming with an obese alter tended to gain fewer pounds, showing heterogeneity in the "freshman 15." McFerran et al. [33] found that eating behaviors were modified according to an alter's apparent body size. Thus, influence may vary in a manner analogous to infectivity factors in infectious disease [34]. Focusing on dyads alone is only appropriate for models where exogenous ties (outside the dyad) can be ignored; researchers are advised to address this question before conducting analyses solely at the dyadic level, since this implies the absence of a larger network [35•].

The next level of interaction is the triad, comprised of three agents. While there are 16 possible triad configurations [36], the most important for studying norms and influence are fully and mutually connected triads (where all three nodes share ties with the other two nodes). Such triads are the smallest completely connected networks ("cliques") possible; they have high rates of social cohesion and homophily. Homophily is the tendency of individuals to select friends who are similar to themselves in background characteristics (as in the old adage "birds of a feather flock together") that can channel and reinforce the flow of important information and health-related behaviors [37, 38]. Based on theories of social capital [16, 39], Simmelian ties [40] and structural balance [41], complete triads that persist over time would exhibit especially strong normative influences (else they would fall apart). The relationship of norms to cohesion is central to Coleman's work on social capital, providing an explanation for the function of norms in maintaining social cohesion through sanctions of norm violation [16]; relevant sanctioning for obesity might include table manners or shaming. However, we know of no attempts to explicitly modeling the role of social triads or cliques in norms or obesity-related behaviors; given that clique membership is tied to (non)smoking behavior [42, 43], this is likely a rich area of research.

Norms and influence also operate at higher levels, where diffusion processes operate, and location (center, periphery) within the network may be important for adoption of new behaviors [44]. Individuals occupying central positions in networks tend to behave in a manner following larger group norms $[45,46]$. Because they are subject to fewer influencers and are less invested in maintaining the status quo, individuals at the periphery may be easier to influence, yet have less influence on the system as a whole [14•]. Tools for identification of network position include block modeling [47] and centrality formulae [28]. Nonetheless, structural positions of nodes may obscure other explanations of position (e.g., homophily), requiring more sophisticated tools that can tease apart processes and handle dyadic and other dependencies [37]. Ties tend to be non-random, and exponential random graph model (ERGM) models can capture departures from 
randomness as well as dependency of ties (dyads), using the $\mathrm{R}$ packages ergm [48] and pnet [49]. The joint co-evolution of ties and behaviors may be examined using the $\mathrm{R}$ package Simulation Investigation for Empirical Network Analysis (R-SIENA) [50]. We emphasize that these models are generative, in the sense that a series of "random" (a misnomer) networks are proposed, then either accepted or rejected based on model fit. Authors who have employed these techniques to study obesity include de la Haye [51, 52], Valente [53], Shoham [54], and Simkins [55].

In spite of the growing interest in social network models to understand obesity, many challenges remain. The Add Health study [30] remains the gold standard for its nearly complete social network data, measured over multiple waves over time. However, the adolescent data were collected in the 1990s and do not capture the current prevalence of adolescent obesity in the USA; the adolescent data further lack detailed information on physical activity and dietary behavior. Additional longitudinal datasets, with detailed information on obesity-related behaviors, are necessary. Another challenge is understanding the impact of online social media (OSM), with a recent Pew survey finding $82 \%$ of teens using OSM, mostly Facebook [56]. The role of OSM in shaping norms around obesityrelated behaviors is unknown, although some preliminary work on tobacco and alcohol use has been done by Moreno [57] and Valente [58]. Finally, if networks are important for structuring norms and influencing behavior, they should also be useful in designing behavioral interventions [14•]. Given that interventions are expensive and some network-based approaches might fail to have an effect, simulations are crucial tools in deciding, which approaches have promise. Simulation models of whole networks have also been created, including Bahr [59], El-Sayed [60], and Shoham (under review). We now turn to one approach to simulation, agent-based models.

\section{Agent-Based Models}

Agent-based modeling (ABM) is a relatively new type of computational simulation model with wide applicability to social dynamics. In an ABM, each individual actor (or "agent") is explicitly represented in computer code. Agents are generally given a set of adaptive rules for interaction with their environment and with other agents. A population of these individuals is simulated as an "artificial society" on a computer, with output through time generated "from the bottom up" by the decentralized interactions and decision processes of the agents [61-64]. In this way, dynamic mechanisms that link individual decision making or behavior to social or population-level outcomes can be effectively studied.

Several features make ABM a potentially powerful approach for the study of social norms and social influence in obesity. First, because each actor is individually represented and modeled in an $\mathrm{ABM}$, the approach permits consideration of substantial diversity among agents - in demography, social exposure, biology, psychology, etc. No aggregation of agents into homogenous pools or compartments is required; both actors and outcomes far in the "tail" of a distribution can be studied effectively. For the study of obesity (characterized in many populations by distributions with substantial skew and variance), and for the study of social influence (where pronounced heterogeneity by social context, age, or psychology may be important), these can be important considerations.

Second, the agent-based approach allows great flexibility in cognitive assumptions about individual decision making and information processing. To translate individual state and external information into a behavior, an individual agent may follow simple heuristic rules, complex cognitive or statistical processing models, or even representations of multiple conscious and unconscious brain processes. Agents may also differ from one another in the form of decision making used, and can adapt not only their behavior but even their rule set through time (for example, by learning). The processes that underlie body weight change and obesity are known to involve multiple brain systems, heterogeneity in decision making, and several forms of dynamic adaptation [65-68].

A third potential advantage of the ABM methodology for the study of social influence lies in its ability to effectively incorporate social and physical space. ABMs provide extensive capability to directly include rich and explicit representations of the context which governs agent interaction and exposure-including geographic spaces [69-71], full or partial social network structures [72], and neighborhood effects [73]. Since the specific form and structure of social networks and geography often determine by whom an individual may be influenced socially, this is a potentially important advantage for modeling social influence effectively.

Finally, ABM provides a powerful platform for the study of co-evolving individual behavior and social context, with dynamic feedback in both directions. ABM includes both a direct representation of the individual level and the ability to capture dynamic changes in population- or neighborhoodlevel outcomes. This enables the approach to capture multiple pathways of feedback between micro-behavior and macrooutcomes. For example, agents can be influenced by extant social norms, by observing distribution across their peers of key characteristics, by direct social contagion, by messaging, or even by the presence or absence of others. At the same time, the model can capture how these environmental contexts change through time as a direct result of the behavior of individual actors. Thus, an individual agent can be influenced by a social norm at time $t$ even as he or she contributes (along with peers) to changes in the state of the norm at time $t+1$. The ABM approach also allows multiple dynamic mechanisms to be layered within the same model — for example, social influence via concurrent processes of homophily and contagion. 
The ABM approach has been widely used within public health for the study of infectious [74-76], although its application to obesity and chronic disease is relatively recent [64]. In social science, ABM has been used extensively to study social norms - including models of social sanctioning [77, 78], segregation [79, 80], cooperation [81, 82], culture [83], agriculture [69], ethnocentrism [84], retirement [85], corruption [86], and civil violence [87].

Several recent studies have applied ABM to the specific topic of social influence in obesity, helping to identify potential mechanisms through which social influence may affect dynamics of body weight. Zhang and colleagues use ABM to study the interaction of homophily and social imitation as dual influences on individual BMI and behaviors such as physical activity and screen time (under review). Bahr et al. [59] explore the implications of similar mechanisms for effective targeting and application of weight management interventions. Hammond and Epstein [88] introduce a specific hypothesized mathematical mechanism ("follow the average") by which individual BMI may co-evolve with population-level aggregate BMI. Chen and colleagues (under review) apply this mechanism to an empirical data set of youth, while Hammond and Ornstein (under review) extend it to include more empirically grounded assumptions and accurate physiology before applying to a different dataset. Opportunities for further application of the technique to gain insight into mechanisms and dynamics of social influence in obesity are substantial and promising, but must overcome potential challenges such as the relative scarcity of longitudinal data revealing dynamic patterns and the limited toolsets and training currently available in the technique.

\section{System Dynamic Models}

System dynamic (SD) models typically divide the population into different groups based on their adoption of a practice, a physical feature (e.g., BMI), or other relevant characteristics. Social influence is then incorporated in at least three distinct ways. First, the number of people in each category may change due to social influence from those in other categories. For example, a large literature model contagion as the process of communication between groups that have adopted a practice or product and those who are potentially interested, and how the rate of conversion depends on both population sizes [89-91]. Obesity has been treated in the same manner, in which a subset of normally weighted individuals is seen to become obese due to interaction with overweight and obese subpopulations [92]. A second group of models captures the dependence of individual's goals on social norms. For example, BMI or weight averages for a group of similar individuals are seen to influence the weight towards which those individuals aspire. One study finds a significant adjustment of energy intake to reach that socially sanctioned average BMI [93]. Thirdly, by categorizing individuals based on their weight groups, the inertial effect of norms are captured in that individuals are naturally staying in their current weight group, unless a separate mechanism changes their weight status. For example, groups' current energy intake or physical activity determines the base level around which the actual values are adjusted using an anchoring and adjustment formulation [94, 95].

System dynamics modeling process may also be used to provide a more nuanced understanding of the mechanisms through which norms are generated and modified [96]. Group model building processes $[97,98]$ identify what social influences different stakeholders in a community perceive and how those influences shape their reactions. Such studies draw heavily on participatory group model building sessions and other qualitative tools, and the resulting qualitative models can inform more nuanced quantitative models with a richer appreciation of social determinants of health $[99,100]$. For example, as part of Envision, Hovmand and Brennan [101] have focused on modeling the social determinants of childhood obesity in a lowincome urban neighborhood. The approach used group model building methods to involve community members including children, youth and young adults, parents, service providers, and clergy in the process of developing a causal map of the influences and consequences of childhood obesity in the community. Specific examples of community based norms that emerged included the fact that while girls tended to seek to lose weight through unhealthy diets, boys tended to seek to gain weight or "bulk up" in an effort to avoid bullying. Other examples included community norms related to "pressure to be cool" that led to fights, shoplifting, and early gang-related behavior. Understanding the causal mechanisms leading to the formation of norms and the consequence of norms at the neighborhood level provides both a better picture of their endogenous influence on obesity trends as well as how to measure them in ways that are most salient to community members.

The structure of SD models is built based on qualitative and process data (e.g., group model building), and social and biological theories (e.g., models of body weight dynamics [102]), and parameters are specified based on theory, expert input, or estimated using aggregate data regarding number of people in different population groups [103], parameterized based on statistical estimates from prior literature [102], or methods that connect individual level dynamics to aggregate models and data [104]. However, the application of these approaches to obesity research is at early stages, and many opportunities exist for incorporating norms into SD models of obesity that are grounded in empirical data and useful for policy analysis. Additionally, SD models could be combined and compared with ABMs in this domain to benefit from the detailed actor network data while keeping the broad model boundary typical to SD models [31]. 


\section{Intervention and Policy Relevance of Models}

Anecdotal evidence suggests that researchers and policy makers are divided regarding the utility of mathematical and simulation models in developing health-related policy and programs. On the one hand, there has been strong support and many examples of useful mathematical models, especially in the areas of infectious disease and tobacco control. On the other hand, evidence-based medicine and evidence-based policy generally demand empirical, not simulated, findings, with randomized intervention trials considered the best evidence for program and policy development.

Mathematical modeling offers many promises, but also faces many challenges as the analysis process often involves making assumptions and subjective decisions (especially when addressing complex public health problems and when data are limited or impossible to collect). However, these factors are in fact among the key reasons why mathematical and simulation modeling is needed. For example, models lay bare assumptions often implicit in other analytical techniques, allowing them to be examined and even tested directly. Similarly, models can help guide future empirical efforts iteratively, by focusing attention on those conceptual variables that matter most, and sometimes even by identifying new ones.

Furthermore, some societal problems are not well served by traditional, quantitative research methods, leading to debate about the methods considered critical for the collection of relevant evidence. Many authors have noted that complex systems solutions are needed to address problems like obesity and related chronic disease [105-107]. Complexity extends to the policy process, which is rarely linear, operates under limited information, and presents temporal challenges including simultaneity of events and heterogeneity of lag times; all of this makes policy evaluation particularly difficult [108].

Stakeholder support has grown for rigorous complex systems thinking regarding health problems, paralleling development in other fields to address the problems of industry engineering, war, disaster response [105]. Examples with a specific health focus include applications to smoking and infectious disease outbreaks. SimSmoke is a simulation model that assesses the impact of past tobacco control policies and generates predictions about the future effect of policies on smoking prevalence and premature mortality attributable to smoking [109]. Soon after influenza emerged in North America in 2009, the World Health Organization (WHO) convened an informal mathematical modeling network of health experts and modeling groups, which made recommendations to limit the spread of the H1N1 virus [110]. The US National Institutes of Health has also supported modeling projects, including the Cancer Intervention and Surveillance Modeling Network (CISNET) [111] and Models of Infectious Disease Agent Study (MIDAS) collaborations [112]. Such efforts have now extended to modeling obesity, including the UK Government sponsored Foresight "Tackling Obesities: Future Choices" study, which applied systems science approaches to obesity and provided recommendations for solutions including government policies [107]. Two recent US Institute of Medicine (IOM) reports further recommend the use of systems science-guided thinking, research, and intervention approaches to fight obesity (IOM, 2010, 2012). Finally, the NCCOR Envision project (which the coauthors are all members of) is applying the methods discussed in this paper to identifying key policy levers for reducing childhood obesity [15].

\section{Conclusions}

The diverse modeling approaches described above can be applied for both discovery and policy analysis in the context of social influence in obesity. The discovery goal can be pursued in the form of both statistical identification of causal mechanisms, and the generation of diverse insights and hypotheses. The network analysis methods allow for teasing out different social influence mechanisms regulating energy intake, physical activity, and other obesity-relevant traits, especially if network data is available over time. Other mechanistic models can also be used for estimating the strength of networks of causal pathways. However, pursuing the statistical identification goal often requires time series data at the right level of granularity and utilization of advanced statistical and estimation methods. Social epidemiologists should make additional use of mechanistic models in obesity research in general and in analyzing social influence hypothesis in particular.

The findings from previous type of research, combined with traditional statistical estimates, can inform the development of realistic agent-based models representing complex interactions among actors. System Dynamics models can also use this data in aggregate and combine it with broad model boundary and feedbacks crossing diverse domains to represent core mechanisms operating on obesity. Both these types of models are suited for the second type of discovery: generating hypotheses on complex interactions that can explain observed regularities, illustrating core dynamics and uncertainties, guiding data collection, and communicating complex insights with different audiences.

A major value of such models is their ability to integrate within a single tool both complex social influence pathways and other types of obesity drivers, from economic factors to the built environment. Such integration is crucial for theoretical understanding if the obesity trend is not the result of any single causal mechanism, but the emergent outcome of complex interactions. The resulting systemic perspective is also indispensable for policy analysis. The broad boundary of these 
models allow for tracking outcomes of interventions that are distant in time or space: from policies that target individuals or small groups (e.g., social network-enabled interventions) to those targeting social institutions (e.g., public campaigns). While increasingly there are examples of mechanistic models applied to well-specified policy problems in the obesity domain, there is much room for models that leverage our enhancing understanding of social influence to design innovative new obesity interventions and assess the existing ones in vitro.

Acknowledgment DA Shoham acknowledges support from a NIH grant (no. R01-HD061978), R Hammond from NIH grant (R01HD061973), H Rahmandad from NIH grant (R21-HL113680), Y Wang from NIH grant (R01-HD064685), and P Hovand from contract number NNSN276200900017C

\section{Compliance with Ethics Guidelines}

Conflict of Interest DA Shoham, R Hammond, H Rahmandad, Y Wang, and P Hovmand all declare no conflicts of interest.

Human and Animal Rights and Informed Consent This article does not contain any studies with human or animal subjects performed by any of the authors.

\section{References}

Papers of particular interest, published recently, have been highlighted as:

- Of importance

1. Wang Y, Beydoun MA. The obesity epidemic in the United States — gender, age, socioeconomic, racial/ethnic, and geographic characteristics: a systematic review and meta-regression analysis. Epidemiol Rev. 2007;29:6-28.

2. Wang Y, Lobstein T. Worldwide trends in childhood overweight and obesity. Int J Pediatr Obes. 2006;1(1):11-25.

3. Burke MA, Heiland FW, Nadler CM. From "overweight" to "about right": evidence of a generational shift in body weight norms. Obesity (Silver Spring). 2009;18(6):1226-34.

4. Lynch E, Liu K, Wei GS, Spring B, Kiefe C, Greenland P. The relation between body size perception and change in body mass index over 13 years: the coronary artery risk development in young adults (CARDIA) study. Am J Epidemiol. 2009;169(7): $857-66$.

5. Maximova K, McGrath JJ, Barnett T, O’Loughlin J, Paradis G, Lambert M. Do you see what I see? Weight status misperception and exposure to obesity among children and adolescents. Int $\mathrm{J}$ Obes (Lond). 2008;32(6):1008-15.

6. Gillett PA. Self-reported factors influencing exercise adherence in overweight women. Nurs Res. 1988;37(1):25-9.

7. Christakis NA, Fowler JH. The spread of obesity in a large social network over 32 years. N Engl J Med. 2007;357(4):370-9.

8. Hernan MA, Hernandez-Diaz S, Werler MM, Mitchell AA. Causal knowledge as a prerequisite for confounding evaluation: an application to birth defects epidemiology. Am J Epidemiol. 2002;155(2):176-84.

9. Pearl J. Causality: models, reasoning, and inference. Cambridge: Cambridge University Press; 2000.

10. Hedström P, Swedberg R. Social mechanisms: an analytical approach to social theory. Cambridge: Cambridge University Press; 1998.

11. Epstein JM. Generative social science: studies in agent-based computational modeling. Princeton: Princeton University Press; 2006.

12. Manski CF. Identification of endogenous social effects: the reflection problem. Rev Econ Stud. 1993;60(3):531.

13. Luke DA, Stamatakis KA. Systems science methods in public health: dynamics, networks, and agents. Annu Rev Public Health. 2012;33:357-76. This review provides a comprehensive overview of the three systems science approaches used in the current paper. Its focus is on the applicability of these tools for different types of health problems. Although the issues of norms and influence are discussed, they are not the focus of the review.

14. Valente TW. Network interventions. Science. 2012;337(6090):49 53. This paper describes the current state of the art in using social networks to design real-world interventions.

15. National Collaborative on Childhood Obesity Research (NCCOR). NCCOR Envision Project. http://nccor.org/projects/ envision.php. Accessed Auguest 23, 2013, 2013.

16. Coleman JS. The foundations of social theory. Cambridge: Belknap; 1990.

17. Meehl PE. Appraising and amending theories: the strategy of Lakatosian defense and two principles that warrant it. Psychol Inq. 1990;1(2):108-41.

18. Abraham C, Michie S. A taxonomy of behavior change techniques used in interventions. Health Psychol. 2008;27(3):379-87.

19. Fishbein M, Ajzen I. Belief, attitude, intention, and behavior: an introduction to theory and research. Reading, Mass.: AddisonWesley Pub. Co.; 1975.

20. Ajzen I. The theory of planned behavior. Organ Behav Hum Decis Process. 1991;50:179-211.

21. Fisher JD, Fisher WA. Changing AIDS-risk behavior. Psychol Bull. 1992;111(3):455-74.

22. Bandura A. Self-efficacy: the exercise of control. New York: W.H. Freeman; 1997.

23. Festinger L. A theory of social comparison processes. Hum Relat. 1954;7:117-40.

24. Berkman LF, Syme SL. Social networks, host resistance, and mortality: a nine-year follow-up study of Alameda County residents. Am J Epidemiol. 1979;109(2):186-204.

25. Carver CS, Scheier MF. Control theory: a useful conceptual framework for personality-social, clinical and health psychology. Psychol Bull. 1998;92:111-35.

26. Kelman HC. Interests, relationships, identities: three central issues for individuals and groups in negotiating their social environment. Annu Rev Psychol. 2006;57:1-26.

27. Scott J. Social network analysis: a handbook. 2nd ed. Thousands Oaks, Calif: SAGE Publications; 2000.

28. Wasserman S, Faust K. Social network analysis: methods and applications. Cambridge: Cambridge University Press; 1994.

29. Burt R. Network items and the general social survey. Soc Networks. 1984;6(4):293-339.

30. Harris K, Halpern C, Whitsel E, et al. The National Longitudinal Study of Adolescent Health: research design (WWW document). http://WwW.cpc.unc.edu/projects/ addhealth/design Accessed 3/28/2011.

31. Rahmandad H, Sterman J. Heterogeneity and network structure in the dynamics of diffusion: comparing agent-based and differential equation models. Manag Sci. 2008;54(5):998-1014. 
32. Yakusheva O, Kapinos K, Weiss M. Peer effects and the freshman 15: evidence from a natural experiment. Econ Hum Biol. 2009;9(2):119-32.

33. McFerran B, Dahl DW, Fitzsimons GJ, Morales AC. I'll have what she's having: effects of social influence and body type on the food choices of others. J Consum Res. 2010;36(6):915-29.

34. Horsburgh C, Mahon B. Infectious disease epidemiology. In: Rothman KJ, Greenland S, Lash TL, editors. Modern epidemiology. 3rd ed. Philadelphia: Wolters Kluwer Health/Lippincott Williams \& Wilkins; 2008. p. 758 p.

35. Shalizi CR, Thomas AC. Homophily and contagion are generically confounded in observational social network studies. Soc Methods Res. 2011;40(2):211-39. This paper is one of the best explanations of the problems of teasing apart peer selection from peer influence in obesity and other health behaviors. The paper makes effective use of causal diagrams to demonstrate why regression-based approaches cannot identify peer influence.

36. Holland P, Leinhardt S. A method for detecting structure in sociometric data. Am J Soc. 1970;76:492-513.

37. Goodreau SM, Kitts JA, Morris M. Birds of a feather, or friend of a friend? Using exponential random graph models to investigate adolescent social networks. Demography. 2009;46(1):103-25.

38. McPherson M, Smith-Lovin L, Cook J. Birds of a feather: homophily in social networks. Ann Rev Sociol. 2001;27:415-44.

39. Putnam RD. Bowling alone: the collapse and revival of American community. New York: Simon \& Schuster; 2000

40. Krackhardt D. The ties that torture: Simmelian tie analysis in organizations. Res Sociol Organ. 1999;16:183-210.

41. Hummon N, Doreian P. Some dynamics of social balance processes: bringing Heider back into balance theory. Soc Networks. 2003;25:17-49.

42. Ennett ST, Bauman KE. Peer group structure and adolescent cigarette smoking: a social network analysis. J Health Soc Behav. 1993;34(3):226-36.

43. Ennett ST, Bauman KE. The contribution of influence and selection to adolescent peer group homogeneity: the case of adolescent cigarette smoking. J Pers Soc Psychol. 1994;67(4):653-63.

44. Valente TW. Network models of the diffusion of innovations. Cresskill, N.J.: Hampton Press; 1995.

45. Alexander C, Piazza M, Mekos D, Valente T. Peers, schools, and adolescent cigarette smoking. J Adolesc Health. 2001;29(1): 22-30.

46. Luke DA, Harris JK. Network analysis in public health: history, methods, and applications. Annu Rev Public Health. 2007;28: 69-93.

47. Borgatti S, Everrett M. Models of core/periphery structures. Soc Networks. 1999;21:375-95.

48. Hunter DR, Handcock MS, Butts CT, Goodreau SM, Morris M. ergm: A package to fit, simulate and diagnose exponential-family models for networks. J Stat Softw. 2008;24(3):nihpa54860.

49. Wang P, Robins G, Pattison P. PNet: Program for the simulation and estimation of exponential random graph $\left(\mathrm{p}^{*}\right)$ models user manual. http://sna.unimelb.edu.au/_data/assets/pdf_file/0006/ 662865/PNetManual.pdf. Accessed August 8, 2013.

50. Snijders T, van de Bunt G, Steglich C. Introduction to stochastic actor-based models for network dynamics. Soc Networks. 2010;32:44-60.

51. de la Haye K, Robins G, Mohr P, Wilson C. Homophily and contagion as explanations for weight similarities among adolescent friends. J Adolesc Health. 2011;49(4):421-7.

52. de la Haye K, Robins G, Mohrd P, Wilson C. Obesity-related behaviors in adolescent friendship networks. Soc Networks. 2010;32(3):161-7.

53. Valente TW, Fujimoto K, Chou CP, Spruijt-Metz D. Adolescent affiliations and adiposity: a social network analysis of friendships and obesity. J Adolesc Health. 2009;45(2):202-4.
54. Shoham DA, Tong L, Lamberson PJ, et al. An actor-based model of social network influence on adolescent body size, screen time, and playing sports. PLoS One. 2012;7(6):e39795.

55. Simpkins SD, Schaefer DR, Price CD, Vest AE. Adolescent friendships, BMI, and physical activity: untangling selection and influence through longitudinal social network analysis. J Res Adolesc. 2013;23:537-49.

56. Madden M, Lenhart A, Cortesi S, et al. Teens, social media, and privacy. http://www.pewinternet.org/ /media//Files/Reports/ 2013/PIP_TeensSocialMediaandPrivacy.pdf.

57. Moreno M̄A, Christakis DA, Egan KG, Brockman LN, Becker T. Associations between displayed alcohol references on Facebook and problem drinking among college students. Arch Pediatr Adolesc Med. 2011;166(2):157-63.

58. Valente T. Variations in network boundary and type: a study of adolescent peer influences. Soc Networks. 2013;35:309-16.

59. Bahr DB, Browning RC, Wyatt HR, Hill JO. Exploiting social networks to mitigate the obesity epidemic. Obesity (Silver Spring). 2009;17(4):723-8.

60. El-Sayed AM, Seemann L, Scarborough P, Galea S. Are networkbased interventions a useful antiobesity strategy? An application of simulation models for causal inference in epidemiology. Am J Epidemiol. 2013;178(2):287-95.

61. Epstein J. Generative social science: Studies in agent-based computational modeling: Princeton University Press; 2006

62. Tesfatsion L, Judd K. Handbook of computational economics: agent-based computational economics (Volume 2): NorthHolland; 2006

63. Epstein J, Axtell R. Growing artificial societies: social science from the bottom up. Cambridge: MIT Press; 1996.

64. Hammond R. Complex systems modeling for obesity research. Prev Chronic Dis. 2009;6(3):A97.

65. Alonso-Alonso M, Pascual-Leone A. The right brain hypothesis for obesity. JAMA. 2007;297(16):1819-22.

66. Appelhans B. Neurobehavioral inhibition of reward-driven feeding: implications for dieting and obesity. Obesity (Silver Spring). 2009; 17(4):640-7.

67. Berridge K, Ho C, Richard J, DiFeliceantonio A. The tempted brain eats: pleasure and desire circuits in obesity and eating disorders. Brain Res. 2010;1350:43-64.

68. Vainik U, Dagher A, Dube L, Fellows L. Neurobehavioural correlates of body mass index and eating behaviours in adults: a systematic review. Neurosci Biobehav Rev. 2013;37:279-99.

69. Axtell R, Epstein J, Dean J. Population growth and collapse in a multiagent model of the Kayenta Anasazi in Long House Valley. Proc Natl Acad Sci U S A. 2002;99 Suppl 3:7275.

70. Epstein J, Pankajakshan R, Hammond R. Combining computational fluid dynamics and agent-based modeling. PLoS One. 2011;6(5):e20139.

71. Heppenstall A, Crooks A, See L, Batty M. Agent-based models of geographical system. New York: Springer; 2012.

72. Eubank S, Guclu H, Kumar VS, et al. Modelling disease outbreaks in realistic urban social networks. Nature. 2004;429(6988):180-4.

73. Auchincloss A, Diez RA. A new tool for epidemiology: the usefulness of dynamic-agent models in understanding place effects on health. Am J Epidemiol. 2008;168:1-8.

74. Epstein J. Modelling to contain pandemics. Nature. 2009;460(7256):687.

75. Epstein J, Parker J, Cummings D, Hammond R. Coupled contagion dynamics of fear and disease: mathematical and computational explorations. PLoS One. 2008;3(12):e3955.

76. Longini I, Halloran M, Nizam A. Containing a large bioterrorist smallpox attack: a computer simulation approach. Int J Infect Dis. 2007;11:98-108.

77. Axelrod R. An evolutionary approach to norms. Am Pol Sci Rev. 1986;80:1095-111. 
78. Macy M, Willer R. From factors to actors: computational sociology and agent-based modeling. Ann Rev Sociol. 2002;28:143-66.

79. Bruch E, Mare R. Modeling segregation processes. New York: Oxford University Press; 2007.

80. Schelling T. Micromotives and macrobehavior. New York: Norton and Company; 1978.

81. Axelrod R, Riolo R, Cohen M. Beyond geography: cooperation with persistent links in the absence of clustered neighborhoods. Pers Soc Psych Rev. 2002;6(4):341-6.

82. Riolo R, Cohen M, Axelrod R. Evolution of cooperation without reciprocity. Nature. 2001;414.

83. Axelrod R. The dissemination of culture: a model with local convergence and global polarization. J Confl Resolut. 1997;41(2):203-26.

84. Hammond R, Axelrod R. The evolution of ethnocentrism. J Confl Resolut. 2006;50(6):926-36.

85. Axtell R, Epstein J. Coordination in transient social networks: an agent-based computational model on the timing of retirement. Washington, DC: Brookings Institution Press; 1999.

86. Hammond RA. Endogenous transition dynamics in corruption. Ann Arbor: University of Michigan; 2006.

87. Epstein J. Modeling civil violence: an agent-based computational approach. Proc Natl Acad Sci U S A. 2002;99(3):7243-50.

88. Hammond R, Epstein J. Exploring price-independent mechanisms in the obesity epidemic. Center on Social and Economic Dynamics Paper. 2007;48.

89. Bass F. A new product growth model for consumer durables. Manag Sci. 1969;15(5):215-27.

90. Peres R, Muller E, Mahajan V. Innovation diffusion and new product growth models: a critical review and research directions. Int J Res Mark. 2010;27(2):91-106.

91. Sterman J. Business dynamics: systems thinking and modeling for a complex world. 1st ed. Boston: McGraw-Hill/Irwin; 2000.

92. Thomas DM, Weedermann M, Fuemmeler BF, et al. Dynamic model predicting overweight, obesity, and extreme obesity prevalence trends. Obesity (Silver Spring). Jun 262013.

93. Rahmandad H, Sabounchi N. Modeling and estimating individual and population obesity dynamics. International Conference on Social Computing, Behavioral-Cultural Modeling, \& Prediction (SBP12). University of Maryland, College Park, MD; 2012.

94. Homer J, Milstein B, . KW, et al. Simulating and evaluating local interventions to improve cardiovascular health. Preventing Chronic Disease. 2010;7(1).

95. Hirsch G, Homer J, Evans E, Zielinski E. A system dynamics model for planning cardiovascular disease interventions. Am J Pub Health. 2010;100(4):616-22.

96. Jacobsen C, Bronson R. Defining sociological concepts as variables for system dynamics modeling. Syst Dyn Rev. 1987;3(1):1-7.
97. Richardson GP. Concept models in group model building. Syst Dyn Rev. 2013;29(1):42-55.

98. Andersen DF, Richardson GP, Vennix JAM. Group model building: adding more science to the craft. Syst Dyn Rev Sum. 1997;13(2):187-201.

99. Rose J, Riolo R, Hovmand P, et al. Modeling the paradox of primary care. In: Strumberg JP, Martin CM, editors. Handbook of systems and complexity in health. New York: Springer Science + Business Media; 2013. p. 815-25.

100. Hovmand P, Brennan L, Chalise N. Whose model is it anyway? In: Lyneis JM, Richardson GP, editors. Proceedings of the 29th International Conference of the System Dynamics Society. Washington, D. C.: System Dynamics Society; 2011.

101. Vennix JAM. Group model building: facilitating team learning using system dynamics. Chichester. New York: J. Wiley; 1996.

102. Hall KD. Predicting metabolic adaptation, body weight change, and energy intake in humans. Am J Physiol Endocrinol Metab. 2010;298(3):E449-66.

103. Osgood ND, Dyck RF, Grassmann WK. The inter- and intragenerational impact of gestational diabetes on the epidemic of type 2 diabetes. Am J Public Health. 2011;101(1):173-9.

104. Fallah-Fini S, Rahmandad H, Chen H, Wang Y. Connecting micro dynamics and population distributions in system dynamics models. In: Eberlein R, Martinez-Moyano IJ, editors. Proceedings of the 31th International Conference of the System Dynamics Society. Cambridge: MA System Dynamics Society; 2013.

105. Bar-Yam Y. Making things work: solving complex problems in a complex world: NECSI-Knowledge Press; 2005

106. Finegood D, Merth T, Rutter H. Implications of the foresight obesity system map for solutions to childhood obesity. Obesity (Silver Spring). 2010;18:S13-6.

107. Vandenbroeck I, Goossens J, Clemens M. Foresight tackling obesities: future choices - building the obesity system map. http://www.bis.gov.uk/assets/foresight/docs/obesity/12.pdf. Accessed August 23, 2013.

108. Leeman J, Sommers J, Vu M, Jernigan J, Payne G, Thompson D. An evaluation framework for obesity prevention policy interventions. Prev Chronic Dis. 2012;9:110322.

109. Levy D, Bauer J, Lee H. Simulation modeling and tobacco control: creating more robust public health policies. Am J Public Health. 2006;96(3):494-8.

110. Van Kerkhove M, Ferguson N. Epidemic and intervention modelling - a scientific rationale for policy decisions? Lessons from the 2009 influenza pandemic. Bull World Health Organ. 2012;90(4): 306-10.

111. CISNET. Cancer Intervention and Surveillance Modeling Network. 2013

112. MIDAS. Models of Infectious Disease Agent Study. http://www. nigms.nih.gov/Research/FeaturedPrograms/MIDAS/. 